\title{
FAMÍLIA E ESCOLA NA SOCIALIZAÇÃO DE MENINAS
}

\author{
Graziela Serroni Perosa*
}

A educação recebida na escola e no interior das famílias produz efeitos sobre as trajetórias individuais das pessoas? Como se dá, por meio delas, a aprendizagem e a incorporação dos estereótipos sociais de classe e gênero? Este artigo apresenta os resultados obtidos por uma pesquisa empírica que identificou e relacionou os modos de socialização de ex-alunas de três escolas confessionais femininas e suas trajetórias socioprofissionais subseqüentes, para interrogar os possíveis efeitos provocados pelos processos de socialização sobre a construção de identidades individuais. ${ }^{1}$

O problema de pesquisa insere-se em uma preocupação mais ampla acerca da relação entre educação e os processos de diferenciação social dos

* Professor-Doutor da Universidade de São Paulo. Av. Arlindo Bettio, 1000 Ermelino Matarazzo. Cep: 03828000 - Campinas, SP - Brasil - Caixa-Postal: 6120. Telefone: (11) 65464521. grazielaperosa@yahoo.com.br

${ }^{1}$ Esta pesquisa foi apresentada como tese de doutorado na Faculdade de Educação da Unicamp, sob a orientação da Prof $f^{\mathrm{a}}$. Dr ${ }^{\mathrm{a}}$. Letí́cia Bicalho Canêdo, em março de 2005. A pesquisa foi financiada pela Fapesp (2000/2004), com apoio da CAPES (2002/2003). Foi elaborada em colaboração com os colegas do Grupo de Estudos sobre Organizações Familiares e Instituição Escolar - FOCUS e integra um conjunto mais amplo de pesquisas sobre os usos que os diferentes grupos sociais fazem da escola. indivíduos (Durkheim, 1955) e, mais diretamente, sobre a participação da educação na produção de desigualdades entre os grupos sociais (Bourdieu, 1967; Ringer, 1979). A elaboração do material empírico foi inspirada pelas contribuições de Pierre Bourdieu, que, por meio do conceito de habitus, atribui uma importância decisiva ao peso da estrutura social sobre a construção das identidades individuais. ${ }^{2}$ Parte-se do princípio de que a posição das famílias e das escolas na hierarquia social estava inscrita e traduzida em suas práticas e estratégias educativas. Os resultados obtidos com esta investigação permitem ressaltar a dimensão não consciente dos processos de socialização e corroboram a tese de que as experiências vividas no interior da família e da instituição escolar constituem-se em filtros por meio dos quais os indivíduos irão poste-

2 "Os condicionamentos associados a uma classe particular de condições de existência produzem os habitus, sistemas de disposições duráveis e transponiveis, estruturas estruturadas predispostas a funcionar como estruturas estruturantes, tanto como princípios geradores e organizadores de praticas e representações que podem estar objetivamente adaptadas ao seu objetivo sem supor uma visada consciente de seus fins... Sem ser em nada o produto da obediência as regras." (tradução livre) (Bourdieu, 1980, p. 88). 
riormente perceber o mundo exterior e basear suas escolhas futuras (Bourdieu, 1980).

As famílias que matriculavam suas filhas nas três escolas privadas analisadas compunham parte dos grupos dominantes e, em menor número, das classes médias. Eram chefiadas por grandes proprietários rurais e urbanos (fazendeiros, industriais, grandes atacadistas do comércio), profissionais liberais (médicos, advogados, engenheiros) e, em menor número, por pequenos e médios comerciantes. Essas famílias estavam em condições de "escolher" uma escola mais austera ou mais "moderna", ou ainda nem austera e nem moderna, simplesmente clássica, dada a forte presença da escola privada no Brasil, que permite às famílias de alta renda controlar o tipo de educação escolar que pretendem para os seus filhos, ajustandoa aos seus projetos de transmissão ou ampliação de uma determinada posição social.

Eram essas famílias de alta renda, na sociedade brasileira, em geral, católicas, que evitavam enviar as meninas para uma escola pública, por volta de 1960, na cidade de São Paulo. Ao matricular as meninas nas escolas católicas privadas da cidade, elas concretizavam uma dupla operação de agregação e segregação social: evitavam o contato das meninas com as crianças e os jovens dos grupos populares, cada vez mais presentes nas escolas públicas, e as inseriam nas redes de famílias conhecidas e (ou) do mesmo grupo social. Em oposição à escola pública, igual para todos, as escolas privadas brasileiras se estabelecem com estilos diferentes, permitindo que ocorra um ajustamento entre as características sociais das famílias e as características pedagógicas dos colégios (Almeida, 1998, p. 272). A convergência entre essas duas instâncias de socialização produz efeitos substantivos para a incorporação e a interiorização dos sentimentos de classe e gênero. É nesse sentido que este estudo pode ser compreendido como uma discussão sobre a participação da escola na produção das diferenças entre os grupos sociais no Brasil.

As três escolas confessionais pesquisadas apresentavam variações na forma de estruturar a experiência escolar de suas alunas, resultando em instituições escolares com estilos distintos, no que se refere à organização do espaço e aos modelos pedagógicos adotados. A dupla hipótese elaborada para dirigir a pesquisa propunha que: a) as variações encontradas na forma de socializar as meninas são tributárias da história de cada instituição e da imagem que suas fundadoras criaram para si e estavam ajustadas às características sociais de frações distintas dos grupos dominantes que lograram recrutar; e b) as diferentes formas de socialização escolar teriam provocado efeitos distintos sobre as trajetórias individuais das ex-alunas das escolas pesquisadas. ${ }^{3}$

O artigo está organizado em três partes. Em um primeiro momento, apresentam-se os dados sobre a história recente das três congregações religiosas que mantinham ou mantêm ainda hoje essas escolas e as características sociais das religiosas e do público que lograram recrutar no período examinado. Em seguida, apresenta-se a modalidade de socialização escolar que cada escola estava encarregada de garantir, compreendidas como o resultado da história particular de cada congregação, evidenciando como se processa o ajustamento entre cada escola e as expectativas educacionais das famílias que recorriam a elas. Na parte final, exploram-se os dados que explicitam a maneira como certas formas de socialização escolar podem estar na base da constituição de determinadas maneiras de se perceber e de agir no mundo à sua volta.

A pesquisa empírica foi realizada, entre 2001 e 2004, com base nas fichas de matrículas das escolas pesquisadas, em documentos escolares e das congregacões religiosas. Pelo correio, foram enviados 82 questionários para ex-alunas das três escolas, nos quais se solicitava um retorno reflexivo sobre as experiências educativas das ex-alunas. Tais questionários produziram dados comparáveis sobre a origem social de três gerações das famílias que recorriam às três escolas e sobre as trajetórias sociais e profissionais das 82 egressas que aceitaram participar da pesquisa. Foram realizadas entrevistas aprofundadas (13) com religiosas, diretoras e ex-professoras das três escolas, visando a reconstruir o estilo pedagógico de cada escola. Seguiram-se entrevistas aprofundadas semi-estruturadas gravadas e transcritas com ex-alunas (18) das três escolas, nas quais explorou-se a trajetória familiar e profissional das egressas das três instituições de ensino. O tratamento dos dados produzidos foi realizado sob a supervisão de Salah Bouedja e Afranio Garcia, durante estagio de doutorado na École des Hautes Études em Sciences Sociales de Paris, com financiamento da CAPES (2002/2003) 


\section{TRÊS ESCOLAS E SUAS FAMÍLIAS}

A chegada das congregações religiosas ao Brasil se intensificou no início do século XX, como conseqüência da institucionalização da escola republicana na Europa e da supressão de muitas escolas confessionais na maioria dos países europeus ocidentais. ${ }^{4}$ Com o fim do padroado e o início do período republicano, as novas congregações desembarcaram em um espaço social livre do arbítrio da monarquia e abriram colégios privados por todo o Brasil. ${ }^{5}$ Essas ordens religiosas encontraram terreno especialmente fértil junto aos grupos dominantes, capazes de arcar com as pesadas mensalidades e que viam com interesse as escolas católicas como lugar ideal para uma formação escolar baseada nos princípios católicos, cuja transmissão era proibida na escola pública republicana. Mais do que isso, a opção dessas famílias pela escola católica expressava uma dupla aposta, pois ela permitia a aquisição de trunfos escolares propriamente ditos (diplomas) e resultava em um investimento na rede de relações sociais das famílias, na medida em que os grandes colégios católicos eram redutos da formação dos grupos de elite no Brasil. Para as meninas, as escolas católicas ofereciam as condições de sociabilidade em um grupo social "elevado" e garantia a familiarização precoce e intensiva com a moral católica, que celebra o eterno retorno da mulher ao casamento e à família. Tais

${ }^{4}$ Ao contrário do que se passou nas áreas de colonização européia na Ásia e na África, no qual o trabalho de evangelização propriamente dita se constituiu no principal instrumento de penetração, no Brasil, a política expansionista da Santa Sé foi marcada pela intenção de expandir o patrimônio, mesmo sem abrir mão das metas de romanização (Miceli, 1988, p.12).

${ }^{5}$ No Nordeste, o principal estado que acolheu tais empreendimentos foi Pernambuco, com quarenta e seis estabelecimentos, contra dezoito instalados no Ceará e cinco em Alagoas. No Sudeste, Minas Gerais e São Paulo lideraram, respectivamente, com noventa e um e oitenta e quatro estabelecimentos mantidos por corporações religiosas. O Distrito Federal possuía quarenta e dois e, no Rio Grande do Sul, concentravam-se cinqüenta e duas ordens religiosas à frente de estabelecimentos de ensino, contra quinze em Santa Catarina e oito no Paraná. Fonte: Estabelecimentos de ensino segundo a dependência administrativa, 1936. Estatísticas do Século XX. Rio de Janeiro: IBGE, 2003. Na cidade de São Paulo, a proliferação de escolas católicas começou lentamente no final do século XIX, ganhou fôlego no início do século XX e seguiu bem acelerada em toda a primeira metade do século XX. A esse respeito, consultar, Perosa, 2004, p.61-76. estabelecimentos de ensino, de um modo geral, representavam uma alternativa para garantir a instrução feminina, sem abrir mão de uma socialização cujo acento fosse moral e não profissional.

Foi nesse contexto que desembarcaram no Brasil as ordens religiosas que fundaram e administraram as três escolas confessionais femininas pesquisadas. As Irmãs de Nossa Senhora das Cônegas de Santo Agostinho, a Congregação das Irmãs Marcelinas e as Irmãs de Santa Cruz vieram respectivamente da Bélgica, da Itália (região de Milão) e Estados Unidos e fundaram, em São Paulo, o Colégio Nossa Senhora das Cônegas de Santo Agostinho, em 1907, o Colégio Santa Marcelina, em 1927, e o Colégio Santa Maria, em 1947. Um exame cuidadoso da história dessas congregações no Brasil mostra que a chegada de cada uma delas na cidade se deu de maneira diferenciada, singularizada tanto pela forma como foram convidadas a vir, como pela localização no espaço geográfico e social da cidade.

As Irmãs Agostinianas foram convidadas pelo abade à frente do principal colégio católico masculino no Rio de Janeiro, ainda na Bélgica. ${ }^{6}$ Com esse valioso apoio, as Irmãs Agostinianas instalam-se provisoriamente na Avenida Paulista e, meses depois, compram um palacete localizado nas imediações de Higienópolis. Para fazer frente à concorrência de um outro internato católico feminino instalado na região, as Irmãs apresentaram o novo colégio como uma filial do Collège NotreDame Des Oiseaux de Paris, mantido pela mesma congregação e voltado para atender às famílias da antiga nobreza e da grande burguesia parisiense. Se considerarmos que o nome da escola, até $1925,{ }^{7}$ era grafado em francês, que as religiosas empregavam o mesmo hábito das Irmãs francesas e o uniforme das alunas brasileiras também se assemelhava ao das alunas francesas, é fácil entender por

${ }^{6}$ A vinda das Irmãs Agostinianas foi intermediada pelos beneditinos à frente do Mosteiro de São Bento na cidade do Rio de Janeiro. Passos da Nossa História, n.3, 1998, p. 1-50.

7 Nomeado inicialmente como Collège des Dames de St. Augustin, apenas em 1925 a escola passou a se chamar Colégio Nossa Senhora das Cônegas de Santo Agostinho (Ibidem, p. 31). 
que a nova escola ficou conhecida simplesmente como Colégio Des Oiseaux e recrutou, para compor seu publico, algumas das famílias mais influentes e ricas de São Paulo. ${ }^{8}$

Cinqüenta anos depois, por volta de 1960, o recrutamento das famílias do Colégio Des Oiseaux não sofrera modificações muito significativas. A principal característica das famílias pesquisadas residia no fato de que elas estavam, há pelo menos duas gerações, em uma posição social dominante. Pais e avós eram grandes proprietários rurais, profissionais liberais na segunda geração, possuíam diversas fontes de renda e, em metade das famílias consideradas neste estudo, ocupavam também cargos eletivos estaduais ou federais. Elas residiam em amplas residências, localizadas nos bairros chiques da cidade. $^{9}$

Uma análise da forma como se deu a chegada das Irmãs Marcelinas ao Brasil mostra que ela diferiu da maneira como as Irmãs Agostinianas se inserem na cidade e no público que logram recrutar. As diferenças começam na forma de vir para o Brasil. Enquanto o convite às Agostinianas partiu de dirigentes eclesiais brasileiros, o das Marcelinas veio do "baixo-clero". ${ }^{10}$ Diferentemente das Irmãs Agostinianas, em condições de se instalar diretamente na próspera São Paulo, as Marcelinas chegaram pelo interior do estado, para também explo-

${ }^{8} \mathrm{O}$ recrutamento das famílias brasileiras para a nova escola começou ainda na Europa. De lá, as Irmãs que haviam estudado no colégio da congregação em Paris teriam escrito para suas colegas do colégio francês brasileiras. A lista de sobrenomes das primeiras alunas da escola (1907) expressa o sucesso das Irmãs no recrutamento das fa-
mílias proeminentes paulistas: Camila de Souza Queiroz, Judith Guedes, Vera do Amaral, Eunice Corrêa, Marina Prado Penteado, Alba de Salles Oliveira, Olívia de Souza Queiroz, Jandyra de Campos, Sarah de Mesquita, Sylvia de Veiga Valladão, Maria Prado Guimarães, Olga de Souza Mursa, Sylvia Guedes, Hélene de Souza Mursa (Ibidem, p. 31).

${ }^{9}$ Das 24 famílias pesquisadas, 20 delas habitavam nos bairros de maior valor imobiliário da cidade, tais como: Higienópolis, Jardim Europa, Jardim Paulistano, Jardim Paulista, Jardim América, Cerqueira César e Pacaembu. Dezesseis, dessas vinte e quatro famílias, possuíam mais de quatro filhos, e quase metade delas contava com mais de quatro empregados domésticos em suas residências, que trabalhavam todos uniformizados (Perosa, op. cit. p. 194).

${ }^{10}$ Um sacerdote italiano, irmão de uma das Marcelinas, negociou a vinda das Irmãs para um encontro com o bispo de uma pequena cidade do interior de São Paulo (Livro do Cinqüentenário, Colégio Santa Marcelina, Publicação Interna). rar o público formado pelas famílias de cafeicultores. ${ }^{11} \mathrm{Em} 1927$, as Irmãs Marcelinas abrem um internato para as filhas de fazendeiros do interior, privilegiando a clientela formada a partir da experiência no interior do estado. Instalam-se em Perdizes, uma região que, à época, não possuía luz elétrica, embora tenha sofrido rápidas transformações nos anos subseqüentes. Quando, em 1934, as Marcelinas abriram o externato para as famílias da classe média, Perdizes já havia se transformado em um bairro composto principalmente por pequenos comerciantes e profissionais liberais (Ponciano, 2001, p. 163).

As famílias que procuravam o Santa Marcelina residiam em sua maioria em Perdizes, eram dirigidas por grandes proprietários rurais, comerciantes bem sucedidos, mas recém-instalados nessa posição social, tanto que o nível educacional da primeira geração (os avós) das famílias pesquisadas dessa escola era em sua maioria o primário e da segunda geração (os pais), não raro, apenas o secundário. Em comparação com o Des Oiseaux, o público do Santa Marcelina era mais heterogêneo, composto por famílias que possuíam um patrimônio mais recente, menos variado, entre os quais o peso relativo dos recursos educacionais tendia a ser mais baixo. No Des Oiseaux, avós paternos e maternos das famílias pesquisadas eram predominantemente brasileiros, em especial paulistas da capital e do interior. Os avôs do Santa Marcelina eram em sua maioria italianos e (ou) vindos de outros países europeus.

Em síntese, tratava-se no primeiro caso de um público formado por uma antiga elite agrária paulista, que possuía, além das propriedades e da diversidade de atividades econômicas desenvolvidas, diplomas superiores prestigiados ${ }^{12} \mathrm{e}$ cargos eletivos. Detinham um capital cultural, simbólico e político, expresso, não raro, pelos sobrenomes

${ }^{11}$ A chegada de congregações estrangeiras nas cidades do interior paulista para a criação de colégios era vista como sinal indelével do progresso e eram recebidas calorosamente pela população local (Leonardi, 2004, p. 77-96).

${ }^{12}$ Dois terços dos avôs considerados no grupo de famílias dessa escola possuíam o diploma de advogado da Faculdade de Direito do Largo de São Francisco (Perosa, 2005, p. 110). 
conhecidos. Já os avôs proprietários rurais do Santa Marcelina eram recém-chegados nessa posição social, tendiam a ter um patrimônio menor, menos diversificado, além de serem menos integrados na sociedade paulista da época. As descrições de duas ex-alunas sobre a ocupação econômica de seus avós, quando postas lado a lado, explicitam as diferenças encontradas entre as famílias dessas duas escolas: "advogado, político, vereador, fazendeiro, cafeicultor, desbravador", relatou uma exaluna do Des Oiseaux sobre seu avô, um paulista nascido em 1879. Uma egressa do Santa Marcelina, por sua vez, descreveu a ocupação de seu avô paterno de origem italiana nascido em 1900, “de bóiafria a fazendeiro de café, de empregado a empregador..." (Perosa, 2005, p. 111).

Já as Irmãs de Santa Cruz, vindas dos Estados Unidos, responsáveis pela criação do Colégio Santa Maria, chegaram a São Paulo em 1946, quando a cidade já se transformara em uma metrópole com cerca de dois milhões de habitantes. Ao contrário das congregações religiosas que saíram da Europa em condições históricas desfavoráveis, essa ordem religiosa chegou ao Brasil após a II Guerra Mundial, dentro da "política da boa vizinhança" desenvolvida pelos Estados Unidos para a América Latina. A vinda ao Brasil foi resultado de um convite de um dirigente eclesiástico para que aqui se estabelecessem, da mesma forma que as Irmãs belgas. Em oposição aos colégios que agora estavam instalados na região mais próxima do centro da cidade, o Santa Maria se estabeleceu em um bairro bem distante do centro, no extremo sul da cidade e basicamente constituído de chácaras. Se, para as Irmãs do Santa Marcelina, chegar às Perdizes, no final dos anos 20 , significou a possibilidade de instalar-se em São Paulo, para as Irmãs de Santa Cruz, a localização distante significou ainda mais. Isso porque, no final dos anos 1940, começava a surgir, em São Paulo, uma fração dos grupos dominantes que via com bons olhos os colégios mais distantes do centro urbano, não apenas porque ele se tornava mais e mais populoso e movimentado, mas também porque passou a ser chique enviar os filhos para estudarem em lugares longínquos, situados em vastos domínios verdes, à semelhança dos grandes internatos americanos descritos por Caroline Persell e Peter Cookson (1985). O programa implementado no local vinha ao encontro da aspiração de famílias interessadas em se diferenciar da antiga elite agrária, gerando novos padrões e expectativas educacionais para as mulheres, católica, mas associada ao modelo feminino emergente: moderna, esportiva, menos formal, fluente no inglês. O comportamento das religiosas americanas contribuía para a imagem de um colégio de freiras arejado, pois as Irmãs eram vistas dirigindo automóveis e nadando, práticas raríssimas entre religiosas desse período.

A articulação do capital social de que dispunham e a imagem de um colégio de freiras "moderno" permitiu que essa congregação religiosa tivesse êxito em atrair uma clientela abastada, com alto nível educacional, ligada de alguma maneira ao pólo intelectual do espaço social (pais e avôs profissionais liberais, mas que também eram ligados a instituições de ensino superior) e interessada em garantir uma educação "moderna", ainda que sob o aval da Igreja Católica. As famílias que procuravam essa escola compunham uma fração relativamente mais nova e mais urbana dos grupos dominantes, entre os quais a ascensão social estava nitidamente ligada à posse de elevadas qualificações educacionais e originalmente menos ligada à posse de grandes propriedades rurais, como no Des Oiseaux. Na realidade, o Santa Maria se estabeleceu atraindo uma parcela das famílias da antiga elite da cidade e as famílias em movimento de ascensão social via a aquisição de diplomas escolares extremamente valorizados, destacando-se, entre eles, o diploma de medicina, na geração dos pais.

As diferenças identificadas entre os três estabelecimentos de ensino - materializadas no endereço das escolas e no público que logram atrair - eram tributárias das características sociais e culturais das religiosas à frente de cada um dos empreendimentos e da maneira pela qual elas dirigiram essas escolas por volta de 1950/1960. No Des Oiseaux, grande parte das Irmãs responsáveis pelo 
colégio, a esta época, provinha de famílias antigas, bem estabelecidas na sociedade paulista e com alto nível educacional. ${ }^{13}$ Essa origem social privilegiada permitia às Irmãs Agostinianas investir no prolongamento dos estudos no exterior, em instituições universitárias católicas. ${ }^{14}$ Possuíam uma experiência educacional muito semelhante àquela que estavam incumbidas de manter nesse estabelecimento de ensino. Famílias e escola agiam como espaços de socialização convergentes, tornando ainda mais efetiva a chance de êxito na transmissão de valores. Alunas e Irmãs pertenciam ao universo social das grandes famílias, antigas e ricas, residentes já há algumas gerações na cidade de São Paulo, ligadas entre si por relações de parentesco, alianças políticas, antigas solidariedades reforçadas pela freqüência aos mesmos estabelecimentos de ensino secundário e superior.

Em contraposição, o recrutamento das Irmãs Marcelinas era muito mais heterogêneo, pois, mesmo se considerarmos que os internatos mantidos pela congregação atraíam filhas de fazendeiros potencialmente interessadas em se converter, os conventos de pequenas cidades da região sul do país respondiam pelo grosso desse recrutamento. ${ }^{15}$ Oriundas de famílias de pequenos agricultores italianos, as Noviças Marcelinas possuíam uma origem social muito mais modesta e provinciana do que a das outras congregações. Quanto à formação

${ }^{15}$ Em Piraí italianos, as Marcelinas instalaram as duas casas que tinham como missão recrutar jovens interessadas em ingressar na vida religiosa. As memórias escritas pelo engenheiro que construiu boa parte das obras das Irmãs Marcelinas são bastante esclarecedoras a esse respeito (Marchetti, 1999).
No caso do Colégio Santa Maria, o grupo de quatro Irmãs americanas que chegaram a São Paulo destacava-se por possuir uma experiência internacional baseada, sobretudo, nas missões na África e na Índia. A maior parte das Irmãs vinha dos Estados Unidos e, depois de alguns anos no Brasil, deslocavam-se para outros países da América do Sul, da África ou retornavam para os Estados Unidos. Diferentemente do caso das outras duas congregações, enraizadas na capital paulista e nas colônias de italianos do sul do país, as Irmãs de Santa Cruz circulavam internacionalmente com regularidade, não apenas por meio das missões nos países africanos, que todas elas exerciam, mas também pelas idas e vindas constantes entre Estados Unidos e Brasil. ${ }^{16}$ Quanto à qualificação educacional, o grupo que chegou ao Brasil já possuía o diploma superior obtido na faculdade mantida pela congregação em Indiana.

\section{OS MODOS DE SOCIALIZAÇÃO ESCOLAR}

Os três estabelecimentos de ensino estavam voltados para atender a famílias católicas, pertencentes a frações distintas do patronato paulista e, obviamente, garantiam uma experiência educacional ajustada às estratégias de reprodução desse grupo social. Aos traços comuns presentes nessas experiências educacionais - entre eles, a segregação espacial que representam as escolas de elite no Brasil-sobrepunham-se variações importantes no modo de socializar as meninas. Tais variações, quando relacionadas às trajetórias sociais subseqüentes das ex-alunas, revelaram-se plenas de significados e efetivamente produziram efeitos diferenciados sobre elas.

Confinadas no interior do seu grupo social, as meninas das três escolas aprendiam, em pequenas doses, a se reconhecer como iguais e a se perceber como distintas dos demais alunos da cida-

${ }^{16}$ Cabe sublinhar, o retorno aos Estados Unidos era, freqüentemente, acompanhado de uma promoção no interior da congregação. Importa reter que a passagem pelo Brasil podia ser vivida como um investimento profissional (Cinqüenta Anos do ... 1997, p. 91). 
de. ${ }^{17}$ Se considerarmos que as famílias de alta renda habitavam os mesmos bairros, freqüentavam as mesmas igrejas, os mesmos clubes, notamos que os colégios privados são apenas parte de um movimento mais amplo de "enclausuramento" da classe dominante, que data do final do século XIX (Baltzel, 1958). Efetivamente, as escolas de elite desempenhavam um papel decisivo na proteção das linhagens familiares, ou seja, na reprodução desse grupo social, na medida em que as alianças matrimoniais tendiam a partir dessa rede de sociabilidade que os colégios estavam encarregados de criar e manter (Persell; Cookson, 2001).

A moral da "boa menina" também reinava nos três estabelecimentos de ensino. Boa parte dessa moral era inculcada por meio de um trabalho diário sobre o corpo, que consistia em buscar aproximar o corpo real do corpo ideal (Bourdieu, 1977). Destacaram-se, aqui, dois aspectos da socialização escolar nessas escolas, emblemáticos do trabalho realizado sobre os corpos, capazes de inculcar o duplo pertencimento social do grupo, de classe e gênero. São eles, a análise da relação com os uniformes e o trabalho à mesa em cada um desses estabelecimentos de ensino. Eles evidenciam como o controle do corpo e de sua apresentação ocupa um lugar central no seio de uma educação burguesa e, particularmente, na educação das meninas no interior desse grupo social (Le Wita, 1988; Frevert, 1991; Pinçon; Pinçon-Charlot, 2000).

A análise comparativa e sistemática dos modos de socializar as meninas nas três escolas pesquisadas traz à tona tanto os traços comuns da educação burguesa, como as variações que ela pode comportar no Brasil, dada a forte presença da escola privada, que permite o ajustamento ainda mais fino entre a posição social das famílias e o tipo de socialização escolar pretendido. No interior dessa socialização de classe e gênero do grupo

${ }_{17}$ A mistura de classes sociais nestes colégios estava completamente fora de cogitação, tanto que, muitas congregações abriram escolas para crianças pobres e para recebelas, novas salas foram construídas ou adaptadas, todos elas, fora da área de circulação das alunas pagantes. Desta maneira, as escolas católicas ressaltavam a dimensão espiritual e desinteressada em relação à educação feminina e recalcavam a dimensão comercial destes empreendimentos. A esse respeito, consultar, Perosa, 2005, p.81. pesquisado, habitavam formas distintas de exercer o controle e de inculcar, nas meninas, os sentimentos e estereótipos de classe e gênero. Tais diferenças, identificadas no modo de exercer a ação pedagógica, estavam adaptadas a condições objetivas tanto das famílias como das escolas encarregadas da educação dessas meninas.

\section{OS UNIFORMES E O CONTROLE DO CORPO}

"O uniforme do Des Oiseaux era um cartão de visitas, eu gostava de vesti-lo, tinha orgulho de ser amarela, azul", informou uma ex-aluna, fazendo referência às fitas - "importadas da Inglaterra", disse outra ex-aluna - que sinalizavam a progressão na seriação escolar. As entradas e saídas do colégio, com as meninas uniformizadas, vestidas com luvas e chapéu, na escadaria do belo edifício, rodeado de jardins que garantiam a distância da rua, transmitiam aos transeuntes a imagem pretendida de homogeneidade social, luxo e distinção. As clássicas saias plissadas e as camisas de manga curta eram acompanhadas de meias três quartos, ponto de honra nos colégios católicos femininos, visto que as pernas eram fortemente relacionadas à sensualidade feminina (Goffman, 1977). O "brilho das cerimônias", nesse colégio, nos disse uma Irmã, devia parte de seu encanto ao cuidado com a apresentação das meninas com uniformes que caprichavam nos modelos e no emprego de tecidos. Por parte das ex-alunas do Des Oiseaux, eles foram citados recorrentemente como parte das melhores lembranças dos tempos de colégio. O prazer em vestir os sofisticados uniformes e a naturalidade para usá-los eram, na realidade, tributários de uma posição social elevada e da relação com o corpo possível a ela: advinham da segurança possível àqueles que controlam as normas de percepção de seu corpo e de si, que contam com os meios de manipular a parte modificável do corpo, ou seja, de investir na aquisição das vestimentas e produzir aquilo que a linguagem ordinária chama de "boa aparência”. O fato é que as meninas do Des Oiseaux estavam menos expostas ao olhar e ao julgamento 
do outro, porque, inconscientemente, elas sabiamse em condições de expor o corpo socialmente legítimo de ser apresentado. Nessa escola, a relação com os uniformes estava encarregada de contribuir para a produção de uma excelência corporal. Longe de ser uma qualidade natural, essa excelência é o resultado da transformação de propriedades sociais em "essência natural": a elegância, a naturalidade, a beleza e a segurança para se apresentar ao olhar do outro (Bourdieu, 1977, p. 52).

Essa experiência é diametralmente oposta à relação de tensão e sofrimento experimentada pelas alunas do Santa Marcelina, entre as quais os uniformes foram mais freqüentemente lembrados, como simplesmente "quentes". Nessa escola, os rituais diários de conferência dos uniformes eram repletos de exigências: as saias deveriam estar todas na mesma altura, bem como as meias três quartos e os "rabos de cavalo" das meninas. "Os cabelos não podiam encostar à gola: ou se prendia, ou se usava curto", relatou uma ex-aluna. O tecido era pesado, as mangas longas, as saias compridas, as meias três quartos, "mesmo no verão, não podíamos arregaçar as mangas", queixou-se uma exaluna. Um trabalho de controle da aparência que se estendia à observação da limpeza das unhas e dos cabelos com profundos significados sobre a experiência escolar desse grupo. Controlar os detalhes da aparência das meninas e expô-las diariamente ao olhar inquisidor do outro geravam uma enorme ansiedade, tanto que houve casos de alunas que saíram do colégio porque o rigor com a limpeza e a arrumação do uniforme estava chegando às raias da loucura. ${ }^{18}$ Esse ritual terminava com a exposição pública daquelas cujo uniforme não atendia a todos os critérios estabelecidos e inculcava, nas meninas, uma sensibilidade e uma vulnerabilidade ao olhar e ao julgamento do outro.

Já no Santa Maria, o uniforme era muito mais "esportivo": saias retas e não plissadas, ca-

${ }^{18}$ Uma ex-aluna nos relatou que seus pais transferiram sua irmã de escola tamanha era a tensão com os uniformes. A menina desejando corresponder às exigências das freiras chegou a exigir dos pais que o uniforme fosse diariamente engomado, exigência que estaria acima das possibilidades da família (Entrevista de pesquisa. São Paulo, março de 2001). misas de mangas curtas, já esboçando um decote e meias soquetes. $\mathrm{O}$ trabalho sobre o corpo, nesse colégio, emergiu dos depoimentos como uma interdição às tinturas de cabelo, unhas e cílios postiços. Enfatizava-se, dessa maneira, um sinal de distinção do colégio, o modelo feminino mais despojado, em oposição ao modelo feminino clássico e tradicional que orientava a maior parte das escolas confessionais femininas. Certamente, na comparação com as demais escolas o trabalho realizado aqui estava muito mais próximo daquele realizado no Des Oiseaux e bem mais distante daquele em operação no Santa Marcelina.

A relação com os uniformes traduzia a relação das Irmãs com o corpo. Se compararmos as experiências opostas da relação com os uniformes no Des Oiseaux e no Santa Marcelina, nota-se que, em ambas as situações, tratava-se de um treinamento para a observação do olhar e do julgamento do outro. A diferença, no entanto, é que, no Des Oiseaux, Irmãs e alunas sabiam-se em condições de impor, sobre o julgamento do outro, uma imagem de si, já que o luxo e a sofisticação dos uniformes faziam do corpo real um corpo legítimo de ser apresentado ao outro. No Santa Marcelina, essa relação estava calcada em uma origem social mais modesta das Irmãs, na qual o temor é ser traído pelo corpo, resultando em uma experiência escolar que tendia a produzir com ele uma relação opressora, sempre exposto à representação dos outros das qualidades desejáveis e legítimas do corpo feminino.

\section{SABER COMER}

Nas três escolas, as refeições eram tratadas como um momento privilegiado da socialização, no qual se transmitia um conjunto de sinais distintivos. A aprendizagem dos códigos de "boa conduta" está relacionada às modificações do comportamento mais permanentes, aqueles que, incorporados, tornam-se quase uma segunda pele. Saber controlar o corpo no momento das refeições significava dispor de um poder importante sobre si mesmo, um controle social amplamente aceito e 
aprovado. Como bem demonstrou Norbert Elias, a etiqueta à mesa se constituiu na sociedade de corte francesa e foi utilizada como uma arma da nobreza diante do seu declínio contra a burguesia ascendente do século XIX (Elias, 1985, p. 94). Mas, de novo, a natureza do trabalho educacional à mesa mostrou-se variada e afinada com as demais distinções notadas.

Para a classe média e para a burguesia em ascensão, tratava-se de adquirir, por exemplo, etiqueta à mesa. Já a antiga elite visava à construção de afinidades entre "iguais". "As meninas do Des Oiseaux sabiam comer", declarou uma antiga professora. "Saber comer" é um desses sinais de distinção social que funcionam como um atestado simbólico da suposta superioridade de alguém em relação aos outros, revelando seu grau de familiaridade com a cultura, de antiguidade nesse meio social, bem como seu distanciamento da natureza. Por meio da aquisição de determinados hábitos à mesa, fundavamse critérios de julgamento sobre as diferenças sociais e sobre uma posição social em relação às outras. No Des Oiseaux, esse momento assumia a forma de uma verdadeira cerimônia. "Asfreiras comandavam tudo fazendo um pequeno 'clac' com um livro de madeira", descreveu uma ex-aluna. As meninas entravam silenciosamente em fila, sentavam-se nos lugares marcados, pegavam os talheres de prata trazidos de casa com o sobrenome gravado e acompanhados da argola do guardanapo. "Alguém nos servia”, conta a mesma ex-aluna. A refeição era um momento ritualizado, com duração e ritmo bem determinados e no qual a fiscalização das regras da etiqueta não era realizada diretamente pelas Irmãs, mas sim pelas meninas umas em relação às outras: "pegaria mal você comer feio", declarou uma exaluna. Tudo funcionava como se não fosse preciso impor as regras de etiqueta, pois as meninas as traziam de casa. Tratava-se de treinar a naturalidade com esse código, cuja aplicação desenvolta era controlada no interior do próprio grupo, o que torna o caráter coercitivo desse momento quase imperceptível e, por isso mesmo, ainda mais eficaz, pois associada à aceitação no grupo e não à obediência a uma autoridade externa.
No Santa Marcelina, o ambiente do refeitório lembrava o espaço de um reformatório, onde todos podiam ser vistos e no qual era preciso ensinar e aprender as boas maneiras. As religiosas tinham, ao mesmo tempo, a função de coordenar o ritual e de inculcar, corrigir e direcionar a aprendizagem da etiqueta à mesa de alunas com origens sociais mais heterogêneas do que nas demais escolas. Por isso, havia sempre uma ou mais Irmãs que acompanhavam as refeições, observando as maneiras à mesa, tocando com uma vara nas costas de quem não mantivesse a postura ereta, cedendo à tentação de relaxar o corpo nos bancos sem encosto do refeitório. Estava em curso uma socialização que enfatizava explicitamente a necessidade de se submeter às regras e à autoridade.

Os depoimentos obtidos permitem reconstruir as características da socialização à mesa no Colégio Santa Maria. "Lá em casa, a gente não podia colocar os cotovelos na mesa. No colégio, só não podia fazer aquilo que incomodasse ao outro. Comer farofa de boca aberta, falar enquanto se comia... essas coisas básicas...”, relatou a filha de um alto funcionário público. Aqui também as Irmãs contavam com o fato de que as meninas eram socializadas em casa com o protocolo de boas maneiras à mesa e, por esse motivo, as marcas do controle podiam ser exercidas de maneira mais discreta, abdicando-se da imposição de castigos físicos, como ocorria no Santa Marcelina. Mas é o depoimento de uma terceira ex-aluna que permite compreender de que forma o tipo de socialização nesse estabelecimento se diferenciava dos demais. Segundo seu relato, em cada mesa, uma das alunas era responsável por apresentar um tema sobre o qual versaria a conversa permitida durante as refeições. Frisou que esse tema deveria ser "ameno, informativo e interessante", por exemplo, a saúde, a utilidade das vitaminas, uma notícia de jornal, etc. Uma outra ex-aluna relatou seu estranhamento inicial diante do fato de que as meninas deveriam servir a mesa e lavar as louças, ao contrário do que acontecia na sua casa. Como as próprias Irmãs, faziam a feira; eventualmente as meninas também eram encarregadas dessas com- 
pras. Assim, no momento das refeições no Santa Maria, estava em jogo muito mais do que o controle da etiqueta padrão, já conhecida, estava em questão a aquisição da habilidade de se responsabilizar perante o grupo. Por meio dessa forma de socializar, o colégio promovia, em doses homeopáticas, a familiarização e a destreza em situações nas quais é necessário tomar a palavra, habilidade tão cara a aqueles que aprendem que é preciso se conter, não se expor, como as alunas das Marcelinas. Por meio dessa socialização, ensinavam às meninas que não se pode ficar parado, acanhado, cumprindo formalmente as etiquetas; ao contrário, é preciso "tomar a palavra”, "ir à feira”. É significativo que uma ex-aluna tenha registrado, no questionário, sua avaliação sobre o que aprendera no colégio: "ter objetivos, ter projetos”.

Importa sublinhar que, nessas diferentes experiências de socialização escolar, aprendia-se muito mais do que o mero conteúdo das disciplinas escolares. Estava em jogo a formação de disposições femininas diferenciadas entre si. Na atmosfera do Des Oiseaux, marcada pelo encantamento do "entre si”, do culto às grandes famílias, à distinção social corporificada no glamour dos uniformes, estavam reunidas as condições propriamente escolares para a formação de mulheres aptas a ocuparem o lugar feminino na reprodução do seu grupo social - qual seja, a de celebrar, com sua beleza e elegância, o sucesso econômico advindo das carreiras masculinas. No Santa Marcelina, as meninas tendiam a estar hipnotizadas pela possibilidade do castigo, o que contribuía para constituição de uma disposição ainda mais dócil, tímida e submissa. No Santa Maria, tudo parecia concorrer para uma educação católica de inspiração mais conquistadora e menos submissa. Foram essas experiências educacionais, presentes na base da interiorização de disposições distintas, que contribuíram para a elaboração de universos de possíveis específicos, tanto no que diz respeito ao ingresso no ensino superior e à atividade profissional, quanto à forma de exercer os papéis sociais da esfera familiar.

\section{DEPOIS DA ESCOLA}

As modalidades de socialização identificadas nessas três escolas para meninas produziram efeitos diferenciados sobre as trajetórias individuais das egressas? As escolhas, as competências e as sensibilidades desenvolvidas expressam a incorporação desta história escolar e familiar? Uma análise dos dados obtidos permite notar que a modalidade de socialização escolar produziu efeitos duráveis sobre os indivíduos, ainda que a história dessas experiências escolares e da origem social das meninas tenha interagido de maneira dinâmica com os demais espaços de circulação do grupo pesquisado. ${ }^{19} \mathrm{O}$ exame dos padrões (i) de ingresso no ensino superior e profissionalização e (ii) de alianças matrimoniais identificados evidencia como cada experiência escolar agiu antecipando e prefigurando um meio profissional e uma forma de colaboração matrimonial específica.

O grupo pesquisado deixou a escola secundária por volta de 1960 e foi efetivamente confrontado com uma expansão do acesso ao ensino superior brasileiro. ${ }^{20}$ À semelhança do que se observa nas estatísticas sobre a distribuição feminina nos cursos superiores no Brasil até a década de 1970, entre as egressas dos três estabelecimentos de ensino, a aquisição dos diplomas superiores deu-se predominantemente nos cursos voltados para receber a clientela feminina, tais como letras, pedagogia, psicologia, história, serviço social e belas artes, diplomas que, em geral, conduziam as moças ao exercício do magistério. Importa sublinhar, entretanto, que, entre as egressas da escola na qual a submissão feminina era um valor exalta-

${ }^{19} \mathrm{Um}$ excelente exemplo de outros espaços de socialização, para além da escola e da família, que provocou efeitos profundos sobre a construção das identidades, foi o movimento estudantil, um espaço de socialização política e moral, com o qual as jovens desse grupo social, inscritas no ensino superior brasileiro, foram confrontadas. Para uma discussão mais aprofundada sobre isso, consultar (Perosa, 2005).

${ }^{20} \mathrm{O}$ percentual feminino entre os matriculados no ensino superior brasileiro, em 1956, totalizava apenas $26 \%$ dos alunos. Em 1961, essa participação subira para $29 \%$ e, em 1966, girava em torno de 31\%. Ao final desta década, em 1971, elas já representavam $40 \%$ do total de matriculados (Barroso e Mello, 1979, p. 48). 
do, o Santa Marcelina, embora quase 70\% das alunas tenham ingressado no ensino superior, a posse desse diploma superior levou-as mais freqüentemente ao magistério primário e secundário, profissão tradicionalmente reservada às mulheres. Entre as egressas do Santa Maria, escola na qual havia uma elaboração de um feminino mais conquistador e menos submisso, apenas três exalunas abdicaram do ensino superior, o índice mais baixo identificado na comparação entre as três escolas. Além disso, os diplomas obtidos deram acesso mais freqüentemente ao magistério no ensino superior, uma carreira fechada para as mulheres da geração anterior e que ocupa uma posição simbólica e materialmente dominante, se comparada ao magistério de ensino primário e secundário. No caso das egressas do Des Oiseaux, metade não ingressou no ensino superior e as demais se subdividiram entre o magistério no ensino superior e o comercio de luxo (decoração, sobretudo), atividade para a qual a rede de relações nas quais suas famílias estavam inseridas se constituiu em um capital inicial valioso.

O prolongamento dos estudos e a possível elaboração de uma carreira profissional interagiram com as alianças matrimoniais do grupo pesquisado. Se considerarmos a militância histórica da Igreja Católica pelo casamento, não surpreende o dado de que, das oitenta e duas ex-alunas pesquisadas nas três escolas, apenas três tenham abdicado do casamento. Entre as egressas do Des Oiseaux, entretanto, as alianças matrimoniais foram socialmente ainda mais homogêneas, com casamentos no interior do mesmo grupo social e que exigiram, não raro, a dedicação integral feminina à carreira masculina, tanto maior quanto mais bem sucedida essa fosse. À semelhança do que descreveu Ute Frevert (1991) sobre as mulheres da burguesia alemã no final do século XIX, a atuação feminina no interior da casa celebrava o sucesso mundano dos banqueiros, dos profissionais liberais e dos industriais afortunados. Esse trabalho, em prol da reputação dos homens do seu grupo social, dava-se não apenas na forma de organizar o interior da casa, a educação aos filhos, mas também nas ações de benemerência, na colaboração dos negócios do marido sem jamais fazer sombra a ele, responsabilizando-se pela economia do lar, pela criação de um ambiente doméstico harmônico, no qual os conflitos estivessem sob controle para que o homem guerreiro pudesse descansar e alimentar-se das mais altas esferas do espírito, em oposição à baixa esfera dos negócios.

As egressas do Santa Maria revelaram-se particularmente dispostas para as profissões intelectuais e para tomar o destino pelas próprias mãos. Elas se casaram mais freqüentemente com cônjuges de fora do seu meio social, embora, nesses casos, eles portassem diplomas escolares socialmente valorizados. Isso viabilizou formas mais flexíveis de composição entre os planos profissionais do casal, tanto que, mesmo quando confrontadas com a necessidade de "acompanhar" o marido, elas se submeteram, como as outras, aos estereótipos de gênero, mas tiveram êxito ao aproveitar tais situações para investir em especializações profissionais ou preferiram reorientar sua atividade profissional a partir delas. Tal forma de reagir favoreceu que interrupções na vida profissional, em razão das carreiras masculinas, não tenham implicado o abandono da inserção profissional. No Santa Marcelina, o modelo de educação encarnado por essa escola, da esposa modesta e submissa, reverberou entre suas ex-alunas, e o custo moral para superar esse modelo foi mais elevado do que nas demais escolas. Tanto que algumas delas, mesmo após um pesado investimento educacional e já em exercício profissional, quando confrontadas com os deslocamentos geográficos imposto pelas carreiras masculinas, não viram outra saída a não ser abandonar definitivamente ou por longos anos o trabalho fora da família.

Por fim, cabe sublinhar como tais escolas de elite, com sua educação total endereçada à pessoa como um todo e em convergência com o trabalho das famílias, agem decisivamente na composição de universos de possíveis. Cada estabelecimento de ensino pesquisado mostrou-se em condições de contribuir para a interiorização de disposições psicológicas, morais e intelectuais específicas, 
presentes na base da construção de uma determinada maneira de se ver no mundo, que orientou as escolhas, as competências e as sensibilidades adquiridas, tanto no que diz respeito à esfera profissional como no que se refere às pressões da vida familiar.

(Recebido para publicação em novembro de 2006) (Aceito em abril de 2007)

\section{REFERÊNCIAS}

ALMEIDA, Ana et. al. Circulação internacional e forma ção intelectual das elites brasileiras. Campinas: Unicamp, 2004. p. 299-315.

; NOGUEIRA, Maria Alice, A escolarização das elites. Petrópolis: Vozes, 2002.

A escola dos dirigentes paulistas. 1998. 292p. Tese (Doutorado) - Faculdade de Educação da Unicamp.

BAUDELOT, Christian; ESTABLET, Roger, Allez les filles! Paris: Seuil, 1992.

BARROSO, Carmem; MELLO, Guiomar N. de. O acesso da mulher ao ensino superior. Cadernos de Pesquisa, [S.l.], n.15, p. 47-75, 1977.

BOURDIEU, Pierre, La distinction. Paris: Ed. Minuit, 1979.

Remarques provisoires sur la perception sociale du corps. Actes de la Recherche en Sciences Sociales, Paris, n. 14 , p.51-54, 1977.

. Le sens pratique. Paris: Ed. Minuit, 1980.

. La noblesse d'état. Paris: Ed. Minuit, 1989.

. O poder simbólico. Lisboa: Difel, 1989.

O capital social - notas provisórias. In: Nogueira, M.A; CATANI, A. (Orgs.) Escritos de educação. Petrópolis Vozes, 1998b. Brasil, 1999.

A dominação masculina. Rio de Janeiro: Bertrand

CANÊDO, Letícia. Gestão familiar e aprendizagem das habilidades para o ofício da política. In: ALMEIDA, A. M.

ڤ. NOGUEIRA, M. A. A escolarização das elites. Petrópolis: Vozes, 2001.

CARVALHO, Marília Pinto de, No coração da sala de aula. São Paulo: Xamã/Fapesp, 1999. p. 19-40.
CINQÜENTA anos do Colégio Santa Maria. São Paulo: 1997. (Publicação interna)

COOKSON, Peter; PERSELL, Caroline. Preparing for power. New York: Basic, 1985.

ELIAS, Norbert. A sociedade de corte. Lisboa: Estampa, 1987. DURKHEIM, Émile. Educação e sociologia. 4.ed. Trad. Lourenço Filho. São Paulo: Melhoramentos, 1955. p. 25-36.

FAGUER, Jean-Pierre. Esposa e colaboradora. In: BOURDIEU, Pierre (Org) A miséria do mundo. Petrópolis: Vozes, 1997.

. Os efeitos de uma "educação total": um colégio jesuíta, 1960. Revista Educação e Sociedade, [S.l.], n. 58, p. 9-53, 1997.

; BALAZS, Gabrielle. O que eles se tornarão? Os efeitos sociais da Câmara. Revista Educação e Sociedade; [S.l.], n. 42, p. 29-52, 1997.

FAORO, Raimundo. Os donos do poder: formação do patronato político brasileiro. 3.ed. Rio de Janeiro: Globo, 2001.

FREVERT, Ute. Classe et genre dans la bourgeoisie allemand au XIX siècle, Genèses, 6, [S.l.], p.5-28, dez., 1991.

GOFFMAN, Erving. La ritualization de la féminité. Actes de la Recherch en Science Sociales, Paris, n.14, 1977.

LEONARDI, Paula. Puríssimo coração: uma escola de elite e sua imagem. Revista Proposições, São Paulo, v. 15, n. 2, p. 77-96, 2004 .

LE WITA, Béatrix. Ni vue, ni connue. Paris: Éditions des Sciences de l'Homme 1988

LIMONGI, Maria Evangelina (Irmã). A primeira fundação brasileira: colégio-mosteiro de São Paulo, 1906. Passos da Nossa História, São Paulo, n.3. p. 17, 1997. (Publicação interna)

MARCHETTI, Domingos; POLINÉSIO M. Julia Memórias a duas vozes. São Paulo: Annablume, 1999.

MICELI, Sergio. Intelectuais e classe dirigente no Brasil. São Paulo; Rio de Janeiro: Difel, 1979.

A elite eclesiástica brasileira. Rio de Janeiro: Bertrand Brasil, 1988. p.12.

MUEL-DREYFUS, Francine. Vichy et l'éternel féminin. Paris: Seuil, 1996.

PASSOS DA NOSSA HISTÓRIA. A primeira fundação brasileira: mosteiro-colégio das Cônegas de Santo Agostinho. São Paulo: Vicariato do Brasil, n.3, p. 1-50,1998.

PEROSA, Graziela S. Grupos familiares, investimentos educacionais e o mercado escolar em São Paulo. Proposições, São Paulo, v.15, n.2 p.61-76, maio/ago., 2004.

Três escolas para meninas. 2005. Tese (Doutorado) - Faculdade de Educação da Unicamp.

PERSELL, Caroline H.; COOKSON, Peter W. Preparing for power. New York: Basic Books, 1985

Pensionnats d'élite: ethnographie d'une transmission de pouvoir. Actes de la Recherches en Sciences Sociales, Paris, n.138, p. 56-65. juin. 2001.

PINÇON, Michel; PINÇON-CHARLOT., Monique. Voyage en grande bourgeoisie. Paris: Quadrige; PUF, 1997. $\overline{1998 .}$

Grandes fortunes. Paris: Petite Bibliothèque Payot, 2000 .

Sociologie de la bourgeoisie. Paris: La Decouverte,

PONCIANO, Levino. Bairros paulistanos de $A$ á Z. São Paulo: Senac, 2001. p. 163.

RINGER, Fritz. Education and society in Modern Europe. Bloomington and London: Indiana University Press, 1979.

O declínio dos mandarins alemães. São Paulo: Edusp, 2001. 443p,

La segmentation des systèmes d'enseignements. $\overline{\text { Actes }}$ de la Recherche en Sciences Sociales, Paris, n.149, p. 6-18, 2004.

SAINT MARTIN, Monique de. Une 'bonne' éducation: les oiseaux, à Sèvres. Ethnologie Française. Paris, v. 20, p. 60-70, 1990.

SCOTT, Joan. Genre: une categorie utile d'analyse historique. Les Cahiers du GRIF, [S.l.], n.37/38, 1988.

TRIGO, Maria Helena Bueno. Os paulistas de quatrocentos anos. São Paulo: Anablume, 2001. 
FAMÍLIA E ESCOLANA SOCIALIZAÇÃO DE MENINAS

\section{Graziela Serroni Perosa}

$\mathrm{O}$ artigo discute as formas pelas quais a educação participa dos processos de diferenciação social e construção de identidades. Focalizouse a experiência escolar e as trajetórias sociais de um grupo de ex-alunas de três estabelecimentos de ensino confessionais femininos de São Paulo, egressas da escola por volta de $1960 . \quad$ Os procedimentos metodológicos incluíram questionários, entrevistas aprofundadas semiestruturadas com ex-alunas, diretoras e ex-professoras, consulta a arquivos escolares e observações de tipo etnográfico. Relacionou-se origem social das famílias e das religiosas às características da formação escolar e os modos de profissionalização das egressas. Os resultados sugerem que os usos feitos pelas famílias da escola privada no Brasil resultam numa experiência educacional homogênea que potencializa os efeitos do processo educativo sobre a modalidade de incorporação dos estereótipos de classe e gênero.

PALAVRAS-Chave: socialização, classe, gender, social reproduction. gênero, reprodução social. and gender stereotypes.

KEYWORD: socialization, class,

\section{FAMILY AND SCHOOL IN THE SOCIALIZATION OF GIRLS}

\section{Graziela Serroni Perosa}

This paper discusses the forms participates in the processes of social à des processus de différentiation differentiation and construction of sociale et de cons-truction d'identités. identities. It was focused on the school L'accent a été mis sur l'expérience experience and the social paths of a scolaire et les trajectoires sociales group of former students of three d'anciennes élèves, issues de trois feminine confessional schools of São établissements d'enseignement Paulo, who left school around 1960. confessionnels féminins de São Paulo The methodological procedures et qui en sont sorties vers 1960. Les included questionnaires, semi- méthodologies utilisées furent des structured in-depth interviews with ques-tionnaires, des entretiens former students, directors and former approfondis et semi-structurés avec teachers, consults to school files and d'anciennes élèves, des directeurs et ethnographic observations. The soci- d'anciens professeurs, des al origin of the families and of the recherches dans les archives nuns were linked to the scolaires et des observations characteristics of the students' ethnogra-phiques. Des croisements academic formation and their ways de données ont été faits sur l'origine of professionalization. The results sociale des familles et des religieuses, suggest that the uses of private schools les caractéristiques de la formation by the families in Brazil result in a scolaire et les manières dont les homogeneous educational élèves se sont professionnalisées. Les experience that potentializes the résultats démontrent que la effects of the educational process on fréquentation des écoles privées par the modality of incorporation of class les familles au Brésil permet d'en arriver à une expérience éducationnelle homogène qui amplifie les effets du processus éducatif quant à l'incorporation des stéréotypes de classe et de genre.

Mots-CLÉs: socialisation, classe, genre, reproduction sociale.

Graz̧iela Serroni Perosa - Doutora em Educação pela Universidade Estadual de Campinas (2005). Mestre em Psicologia Escolar e do Desenvolvimento Humano pela Universidade de São Paulo (1998). Graduada em Psicologia pela Pontifícia Universidade Católica de Campinas (1992) Professora da Escola de Artes, Ciências e Humanidades da Universidade de São Paulo. Tem experiência na área de Educação, com ênfase em Psicologia e Sociologia da Educação, atuando principalmente nos seguintes temas: educação e estratificação social, aprendizagem das diferenças sociais, relação família/escola em diferentes grupos sociais e construção das relações de gênero. 